\title{
La Dimension Interculturelle d'Un Cours En Ligne De Français Aux Objectifs Universitaires
}

\author{
Vitalina Bahneanu \\ Docteur ès lettres, Maître de conférences \\ Université d'Etudes Européennes de Moldova, Chisinau, République de Moldova \\ francofonie.bahneanu@mail.md
}

\section{Doi:10.5901/jesr.2013.v3n7p355}

\section{Résume}

On s'interroge beaucoup sur les façons d'enseigner la culture, l'interculturel, en classe de FLE mais assez peu finalement sur la façon dont la culture influence les façons d'enseigner. Le Cadre européen commun de référence pour les langues nous parle de compétences interculturelles très abstraites et enfermées dans des grilles quelquefois étrangères aux pratiques professionnelles. Une observation rigoureuse des façons d'enseigner dans différentes cultures et dans différents contextes, avec une méthode et un protocole spécifiques (des audio et vidéos de classe, jeu de rôle, simulation, analyse du discours) peut aider à se défaire de nos certitudes sur les bonnes façons d'enseigner ou d'apprendre.

Mots clés: La démarche interculturelle, stéréotypes des cultures, dialogue interculturel, négociation interculturelle.

La démarche interculturelle se propose de déconstruire certaines images excessivement stéréotypées des cultures pour découvrir leur complexité et pour établir un véritable dialogue interculturel à travers la prise de conscience de ses propres cadres de référence, la capacité d'assumer le point de vue de l'autre et le développement de compétences liées à la négociation interculturelle.

Ce type de démarche vise la capacité de décentration de l'apprenant, qui renvoie à la capacité de rejeter les préjugés, d'abandonner, pour un moment, sa propre vision du monde pour assumer celles d'autres cultures et apprendre d'autres manières de sentir, d'appréhender la réalité, de penser et d'agir. A travers la connaissance plus approfondie d'autres cultures, se développent des attitudes et des dispositions d'ouverture interculturelle ainsi que des savoir-faire en lien avec les dimensions culturelles.

Actuellement, on s'accorde à dire que l'on ne peut séparer langue et culture. L'apprentissage de la culture doit donc être intégré dans l'apprentissage de la langue, et dépasser le niveau de « civilisation », pour aborder des éléments plus profonds tels les systèmes de valeurs ou de croyances, et la vision du monde. Si la langue influence la manière dont nous nous comportons et percevons les choses, la culture est aussi inhérente à la langue même, à sa structure, à son vocabulaire, ses expressions, et peut être enseignée en même temps que la langue. Selon Lambert (1972), l'acquisition d'une langue peut être considérée comme une série de barrières à franchir, avec la langue et la culture comme barrières principales. La culture semble être une barrière plus résistante et plus difficile à franchir. L'apprentissage culturel implique que l'apprenant assimile certains aspects d'une culture différente, aspects influençant la langue et le comportement.

A l'heure où la mondialisation se généralise, les frontières géographiques deviennent quasiment virtuelles c'est la diversité culturelle qui constitue, en quelque sorte, une autre frontière, plus subtile et plus fondamentale qui continue à persister. Parfois ignorée ou négligée, cette barrière culturelle nécessite une étude approfondie, pragmatique et théorique, étant donné le fait que, lors du processus de la formation, plus particulièrement celle universitaire, tout apprenant doit être placé dans un espace interculturel et orienté vers une formation dépassant la dimension monolingue d'une société concrète. Autrement dit, l'apprenant d'une langue étrangère et d'un domaine professionnel concret, réalisé dans sa langue maternelle et parallèlement dans une langue étrangère, peut être considéré comme un «intermédiaire culturel ».

\section{Le rôle de l'interculturalité dans la formation universitaire actuelle}

La notion d'interculturel ou d'interculturalité est largement exploitée dans les écrits des chercheurs contemporains. Une des définitions du terme nous informe que « L'interculturalité est l'ensemble des relations et interactions entre des 
cultures différentes, générées par des rencontres ou des confrontations, qualifiées d'interculturelles. Impliquant des échanges réciproques, elle est fondée sur le dialogue, le respect mutuel et le souci de préserver l'identité culturelle de chacun. »

L'implication de l'interculturalité au niveau linguistique, philosophique, traductologique et sans doute à celui didactique, suscite toujours beaucoup de questions et nécessite des interventions, des solutions (encore plutôt partielles) et des explicitations signées par des spécialistes de différents domaines. Ces recherches ont l'intention de proposer des instruments capables à faciliter, à régler, à améliorer la communication et l'intercompréhension. Sans doute, le processus de recherche débouche sur des expériences souvent enrichissantes grâce aux informations acquises qui résultent du métissage interculturel. Ce résultat répond en même temps aux attentes éducationnelles et explique la motivation et la condition de l'attribution d'un espace prioritaire à l'interculturalité dans la formation universitaire, ciblée sur la professionnalisation dans un cadre socioculturel actualisé.

On a bien raison de considérer que l'interculturalité est conditionnée par nombreux facteurs venant soit de différentes perceptions de la culture, soit des obstacles de la langue, ou encore de l'absence de politiques gouvernementales, des hiérarchies sociales et économiques. La formation axée sur une approche interculturelle a le but de familiariser les apprenants avec la problématique des échanges réalisés dans un espace de contact des langues, des cultures, des mentalités.

Le discours économique et surtout celui de droit sont porteurs d'une dimension culturelle évidente qui se reflète non seulement dans les mots ou les termes propres à un système juridique ou économique, mais aussi dans la façon de les véhiculer. La qualité de l'intercommunication des sujets appartenant à des réalités socioculturelles différentes est alors étroitement conditionnée par le volume de connaissances interculturelles qui contribuent à l'éradication des obstacles y compris dans la communication professionnelle.

Pour surgir dans la limite du possible les frontières matérielles et culturelles existant entre les sociétés on fait actuellement recours à des instruments universels qui sont inclus aujourd'hui dans le circuit de la communication via l'Internet et qui offrent différentes plates-formes destinées au de partage de connaissances et de formation, d'information, d'échanges d'idées et de valeurs etc. L'émergence d'Internet a considérablement touché la formation universitaire, car le nombre des établissements proposant des cours en ligne est de plus en plus important et leur aire géographique est actuellement bien étendue et variée.

L'Agence Universitaire de la Francophonie investit solidement dans l'espace numérique et nombreux projets qui sont en déroulement ciblent des formations des enseignants venant de différents domaines en vue de l'utilisation des TIC pour des cours magistraux ou des travaux dirigées, mais aussi pour la recherche universitaire, pour les activités individuelles des étudiants, pour la formation continue etc. En plus, cet instrument assure un solide gain financier, car il s'agit des économies importantes sur le coût du matériel utilisé pour les éditions des supports papier. Mais le plus grand bénéfice revient sans doute aux destinataires de ces élaborations en ligne grâce au fait que les cours répondent aux attentent d'un public bien nombreux mais aussi très hétérogène qui fait preuve d'une prise de conscience juste et plus profonde des facilités issues de l'application des possibilités de l'informatique.

Les conditions de la communication virtuelle déterminent le respect de plusieurs facteurs parmi lesquels la spécificité socioculturelle ainsi que celle sectorielle ou disciplinaire. Les nouveaux acteurs-formateurs tentent d'organiser les chaînes adressés à un nouveau type d'acteurs-destinataires, en faisant recours aux maximum de possibilités offertes par l'Internet : les moteurs de recherche, les moteurs de blogs, le skype, les forums de discussions, les réseaux sociaux, les plates-formes utilisées pour des formations etc. Ce nouveau principe d'organisation de la communication pousse à la réorganisation du système proprement dit, supplantant de plus en plus celui traditionnel, hiérarchisé et en le remplaçant par un autre, technologique. Avec ça, le système devient plus ouvert, ayant un nombre augmenté d'acteurs connectés, qui sont anonymes, donc indépendants. En même temps, le système de communication et de formation virtuelle a le but de stimuler la mise en application des mécanismes d'auto-organisation des apprenants.

\section{L'espace interculturel d'un cursus en ligne}

Les priorités indubitables de l'Internet nous ont motivé de nous organiser pour la conception des cursus en ligne ayant le statut de sources supplémentaires dans la formation professionnelle encadré dans le parcours universitaire. Vu le caractère international de l'équipe des concepteurs, on a décidé d'introduire dans chaque unité du cursus un espace ou soit placée l'information valorisant la dimension intersociale et interculturelle des sujets abordés dans l'unité respective.

Les concepteurs du cours trouvent absolument nécessaire que les futurs spécialistes en droit et en économie possèdent des informations supplémentaires sur différents aspects de la vie professionnelle dans des pays européens, 
ce qui contribuera à l'élargissement de leur horizon professionnel et encyclopédique. Dans ce but nous avons élaboré des fiches interculturelles par disciplines qui figurent à la fin des unités et dont la thématique prévoit des sujets qu'on a considéré prioritaires ou, au moins, intéressants pour les apprenants. Chaque espace contient des unités qui seront réunies sur le site universitaire et déclinées par disciplines et par thématiques.

\section{L'approche interculturelle abordée par le biais des registres sociaux (le langage juridique)}

La comparaison des systèmes du droit français et moldave permet certainement de se rendre compte qu'ils sont bien proches, étant donné le fait qu'ils se réunissent dans la même famille de droit romano-germanique. Aussi simple qu'il soit parfois de comprendre certaines collocations, comme par exemple casser un jugement, la situation est tout à fait différente pour des unités comme dresser une minute et la tâche de l'enseignant/apprenant s'avère plus difficile. Ainsi la combinaison dresser une minute est pratiquement introuvable dans la plupart des ouvrages terminographiques traitant le domaine du droit, alors le sens de cette expression peut se révéler peu évident pour un locuteur étranger.

Dans l'actualité mondiale de notre époque, les rapports interculturels sont envisagés sous différentes formes : des conflits, contrat, mariage etc. Et il est fréquent que cette perception soit étayée et encouragée par des expériences personnelles difficiles, vécues au contact des cultures différentes. Un exemple relevant représente l'organisation juridictionnelle française qui n'est pas couverte par une même réalité dans la République de Moldova. La justice en France est rendue par des tribunaux, qui selon le droit français est une juridiction formée d'un ou de plusieurs magistrats qui jugent ensemble, alors qu'en République de Moldova la justice est rendue par l'institution nommée instanţă de judecată ou judecătorii, qui est une « Institution judiciaire ayant comme attribution de base de trancher (en première ou dernière instance) certaines causes prévues par la loi ».

Une autre réalité de la vie juridique française est constituée par l'acteur connu sous le nom de huissier - Officier ministériel ayant pour charge de constater des faits, de signifier les actes de procédure et de mettre à exécution les décisions de justice et les actes authentiques ayant force exécutoire. Dans le système du droit moldave, on trouve une activité et des attributions similaires, correspondant à celles de executor judecătoresc.

Le langage juridique ne s'utilise pas en exclusivité dans des situations officielles. Les cas ne sont pas rares où l'on enregistre des mélanges des registres fonctionnels dans les textes qui foisonnent dans le domaine juridique.

Beaucoup de notions juridiques ont un équivalent dans le langage familier, surtout qu'ils sont utilisés dans des blogs personnels ou autres documents du même type. Analysons un fragment qui le prouve parfaitement :

\section{L'affaire a Suivre}

\subsection{Justice!}

Nous y sommes, mon avocat a posé mon dossier au Conseil des Prud'hommes.... le 23 juin est la date de la déclaration de la guerre... Je déclenche pour de bon les hostilités.

La conciliation obligatoire est prévue au 24 juillet... mais je ne pense pas négocier, tout bien réfléchi, je ne suis pas à vendre et on m'a pris trop longtemps pour un débile... Je reprends du poil de la bête et j'ai le temps de me renseigner...

Pour la cerise sur le gâteau, il ne faut pas se tromper... prendre un peu de sou tout de suite et être imposé sur les sommes ou attendre des mois les délibérés d'un tribunal et être exonéré....

car Le fisc admet aussi l'exonération des dommages-intérêts alloués par les tribunaux en cas de licenciement sans cause réelle et sérieuse, de licenciement abusif ou d'inobservation de la procédure de licenciement... là est la question... Suis-je à brader ? ou pas ???

Le principal maintenant n'est pas là... on m'a suffisamment dénigré et maintenant, on essaye de négocier, les dirigeants auraient-ils des doutes sur leur décision, leur comportement sûrement pas, malheureusement ils ont poursuivi et d'autres sont sur la sellette, mais il faudra qu'ils rendent des comptes... et en ont-ils les moyens ???

Je veux qu'on reconnaisse que j'ai été floué, et que JUSTICE me soit rendue.

(Source : http://www.easydroit.fr/ consulté le 30 mars 2013)

Nous avons placé dans un tableau quelques expressions du registre familier en proposant leurs équivalents au niveau du langage standard et la traduction en roumain: 


\begin{tabular}{|l|l|l|}
\hline \multicolumn{1}{|c|}{$\begin{array}{c}\text { Niveau du langage } \\
\text { standard }\end{array}$} & Niveau du langage familier & Traduction en roumain \\
\hline une amende & une prune & ştraf, gloabă (învechit) \\
\hline être incarcéré & aller à l'ombre & a sta la răcoare \\
\hline flagrant délit & Etre pris la main dans le sac & a fi prins cu mîţa-n sac \\
\hline gardien de paix & Flic & copoi, sticlete \\
\hline
\end{tabular}

Le respect de la dimension culturelle propre à chaque pays, vue dans toute sa diversité fonctionnelle, reste une condition sine qua non dans le processus d'enseignement/apprentissage du français de spécialité, y compris celui du droit ou de l'économie. Sa prise en compte est essentielle, car lorsqu'elle est mal gérée, les tensions et les frustrations qu'elle suscite peuvent conduire à l'intolérance, au repli identitaire ou communautaire, au racisme, ou plus généralement à ce qu'on appelle «l'ethnocentrisme ».

\section{Conclusion}

Les cours en ligne constituent des plates-formes qui catalysent la formation professionnelle et intellectuelle des apprenants. Ceux-ci sont placés dans un espace qui intègre tant les aspects essentiels de leur future profession que des situations promouvant la spécificité d'une communication qui se produit entre les acteurs venant d'une autre dimension culturelle et sociale, donc partageant des versions différentes du monde. Ces supports dotent les apprenants des outils métacommunicatifs qui pourront être mis en application dans les situations de communications professionnelle interculturelle.

\section{References}

http://www.toupie.org/Dictionnaire/Interculturalite.htm (consulté le 25 mars 2013)

http://www.easydroit.fr/ (consulté le 20 avril 2010) 